\title{
TARI JATHILAN SEBAGAI TERAPI PADA PENDERITA REHABILITAN GANGGUAN JIWA
}

\author{
Eshry Febyulan P.A*) \\ Jurusan sendratasik FBS, Universitas Negeri Semarang \\ Email: oshyzaky@gmail.com \\ M. Jazuli**) \\ Email: muhjaz61@gmail.com \\ Dosen Jurusan Sendratasik FBS, Universitas Negeri Semarang
}

\begin{abstract}
ABSTRAK
Tari Jathilan merupakan salah satu kesenian kerakyatan yang digunakan sebagai salah satu media terapi pada pasien rehabilitan gangguan jiwa (Skizofrenia) dalam upaya penyembuhan kejiwaan pasien di Rumah Sakit Jiwa Magelang. Tujuan penelitian untuk mendeskripsikan proses terapi tari dan menjelaskan manfaat yang ditimbulkan pada rehabilitan gangguan jiwa (Skizofrenia). Penelitian kualitatif pengumpulan data dilakukan menggunakan observasi, wawancara dan dokumentasi. Teknik keabsahan data yang digunakan menggunakan triangulasi metode. Hasil penelitian dengan mendeskripsikan proses terapi yang meliputi kegiatan pendahuluan, inti, dan penutup serta manfaat dari terapi tari yaitu memperbaiki koordinasi gerak pasien, konsentrasi berfikir, menyalurkan energi positif pada tubuh pasien, meningkatkan kemandirian pasien.
\end{abstract}

Kata Kunci: Tari Jathilan, Terapi, Gangguan Jiwa (Skizofrenia), Proses Terapi Tari

\section{PENDAHULUAN}

Tari mempunyai arti penting dalam kehidupan manusia karena dapat memberikan berbagai manfaat, seperti sebagai hiburan dan sarana komunikasi (Jazuli, 2008:1). Tari dapat diterapkan di sekolah atau lembaga-lembaga tertentu sebagai salah satu pelajaran atau media untuk menyampaikan maksud dan tujuan tertentu. Tari adalah ekspresi jiwa yang dituangkan lewat gerak melalui tubuh manusia yang mempunyai makna tertentu didukung oleh musik pengiring dan kostum, serta properti lain di tempat/ruang tertentu (Hartono, 2013:55). Bicara mengenai seni tari khususnya, jenis tari ada beberapa macam salah satu misalnya tari kerakyatan. Salah satu contoh dari tari kerakyatan yaitu Tari Jathilan.
Tari Jathilan merupakan kesenian rakyat yang sudah lama ada di Jawa. Tarian jathilan dilakukan dengan cara penari menaiki kuda kepang. Tari Jathilan awalnya digunakan sebagai sarana upacara ritual yang sifatnya magis. Namun berdasarkan perkembangan jaman dan kebutuhan maka kesenian jathilan tidak saja digunakan sebagai acara ritual, kini jathilan menyesuaikan kondisi perubaan jaman (Kuswarsantyo, vol 01, No.01 2014: 48). Semakin populernya seni dalam kehidupan masyarakat dapat membuka wawasan baru tentang kegunaan seni. Seni dapat dipakai sebagai terapi bagi penderita gangguan kejiwaan. Penggunaan seni dalam psikoterapi merupakan salah satu media psikologi dengan seni. 
Kerasnya kehidupan yang dialami, bermunculan berbagai bentuk gangguan kejiwaan, seperti stres, depresi, alienasi (keterasingan), kehilangan makna hidup, dan sebagainya. Adanya masalah manusia itu di satu sisi dan adanya pemanfaatkan karya-karya seni dalam upaya penyembuhan gangguan kejiwaan manusia di sisi lain mendorong lahirnya apa yang disebut sebagai terapi seni.

Terapi melalui gerak dan tari, musik, puisi sebagai metode yang dapat memantapkan kesehatan tubuh, emosi, spiritual, dan kesadaran hubungan tubuh dan jiwa.

Di Rumah Sakit Jiwa Magelang, Tari Jathilan bukan hanya sebagai media pertunjukan namun digunakan sebagai media terapi bagi penderita rehabilitan gangguan jiwa. Gangguan jiwa yang mengikuti terapi merupakan gangguan jiwa Skizofrenia yaitu pasien yang mengalami gangguan dengan serangkaian simtom yang meliputi gangguan konteks berfikir, bentuk pemikiran, persepsi, efek, rasa terhadap diri, motivasi, perilaku dan fungsi interpersonal (Halgin, 210:44).

Keuntungan dari terapi tari dalam mengobati penyakit mental telah memberikan cara untuk berbagai teknik sebagai salah satu cara membebaskan dari jiwa seseorang yang terganggu. Atas dasar gambaran di atas peneliti tertarik untuk meneliti "Tari Jathilan Sebagai Terapi Pada Penderita Rehabilitan Gangguan Jiwa Skizofrenia di Rumah Sakit Jiwa Magelang".

Tujuan penelitian yaitu guna mendeskripsikan proses terapi pada penderita rehabilitan gangguan jiwa skizofrenia melalui Tari Jathilan di Rumah Sakit Jiwa Magelang serta menjelaskan manfaat yang ditimbulkan dari proses terapi pada penderita gangguan jiwa skizofrenia melalui Tari Jathilan di Rumah Sakit Jiwa Magelang.

Manfaat penelitian bagi penderita gangguan jiwa skizofrenia sebagai sarana penyembuhan psikis yang dialami, sedangkan bagi pendidik ditemukan banyak kendala yang dialami oleh seorang pengajar dalam memberikan pelatihan seni tari kepada seorang penderita gangguan jiwa skizofrenia yang dalam menyampaikanya butuh kesabaran dan keahlian agar pasien dapat merasakan ketenangan yang mempengaruhi psikis.

\section{Landasan Teori}

Kesenian Jathilan adalah jenis kesenian tradisional kerakyatan yang berupa tari seperti jenis tari yang lainnya. Tari tradisonal rakyat mengungkapkan perasaan gembira, kebersamaan, kerukunan, dan kesederhanaan yang berupa gerakan tari yang sangat sederhana (Herawati, 2009:29).

Dalam konteks yang masih sama Soeryodiningrat memberi arti bahwa tari adalah gerak-gerak dari seluruh anggota tubuh atau badan yang selaras dengan bunyi musik, diatur oleh irama yang sesuai dengan maksud dan tujuan di dalam tari (Jazuli, 2008:6). Tari adalah gerak yang terjadi karena adanya irama yang mengatur dan dibentuk sedemikian rupa sehingga menjadi gerak yang indah. Gerak tari sebagai gerak yang indah untuk mewujudkan pengalaman yang dapat dimengerti dan dihayati orang lain.

Dunia kesehatan mental terdapat berbagai macam jenis gangguan kejiwaan yang menyerang penderita gangguan jiwa. Salah satunya adalah gangguan jiwa skizofrenia. Skizofrenia merupakan salah satu dari berbagai macam jenis gangguan psikosis. Psikosis biasanya diklasifikasikan menjadi dua kelompok utama, yakni psikosis organik dan psikosis fungsional (Semiun, 2006:19). Pengertian skizofrenia yaitu gangguan dengan serangkaian simtom yang meliputi gangguan konteks berfikir, bentuk pemikiran, persepsi, efek, rasa terhadap diri, motivasi, perilaku, dan fungsi interpersonal (Halgin, 2010:44). Skizofrenia ditandai dengan hilangnya tingkat fungsi sebelumnya, gangguan komunikasi, delusi dan halusinasi yang 
aneh, penyimpangan persepsi dan emosi (Litfiah:145).

Arif (2006:3) dalam skizofrenia adanya gangguan yang ditandai dengan gejala positif dan gejala negatif :

1) Gejala Positif, gejala positif seperti pembicaraan yang kacau, delusi, halusinasi, gangguan kognitif dan persepsi.

2) Gejala Negatif, gejala negatif seperti avolition (menurunya minat dan dorongan), berkurangnya keinginan bicara, dan miskinya pembicaraan, afek datar, serta tergangguanya relasi personal.

Penanganan dalam gejala psikotik negatif dapat dilakukan salah satunya melalui psikoterapi. Psikoterapi ialah metode penyembuhan dari gangguangangguan penyakit-penyakit jiwa (Kartono, 2012:267). Dengan berbagai macam model terapi yang ada, dalam proses terapi pada penderita rehabilitan gangguan jiwa (Skizofrenia) melalui Tari Jathilan di Rumah Sakit Jiwa Magelang ini memfokuskan kepada terapi perilaku.

Terapi tingkah laku adalah penerapan aneka ragam bentuk dan prosedur yang berakar pada berbagai teori tentang belajar. Pendekatan ini, telah memberikan sumbangan baik pada bidang klinis maupun pendidikan (Corey, 2010: 193). Para terapis perilaku mengidentifikasikan faktor situasional tepat yang terkait dengan perilakuperilaku bermasalah dan mengajarkan keterampilan sosial dan mengatasi masalah (Palmer, 2010:17).

Dalam pelaksanaan terapi tari pada penderita rehabilitan gangguan jiwa (Skizofrenia) di Rumah Sakit Jiwa Magelang melalui Tari Jathilan ini yaitu menggunakan konsep belajar. Karena pada tujuan penyembuhan kondisi normal pasien yaitu sebagai terapi perilaku yang berakar pada teori belajar. Dalam proses terapi ini di dalamnya terdapat aspek belajar seperti:
(1) Terapis

Terapis merupakan seseorang yang memberikan klien mereka tugas yang menantang gagasan dan keyakinan yang ada dan tugas yang mempresentasikan perubahan dalam pola perilaku kebiasaan mereka (Palmer, 2010:26).

(2) Rehabilitan

Rehabilitan merupakan penderita atau pasien yang mendapatkan rehabilitasi.

(3) Tujuan

Tujuan adalah pedoman sekaligus sebagai sasaran yang akan dicapai dalam kegiatan belajar mengajar. Tercapainya tujuan sama halnya keberhasilan pengajaran (Djamarah, 2010:109).

(4) Bahan Pelajaran

Salah satu tugas guru yang utama adalah menyampaikan materi pelajaran. Untuk itu guru harus bisa memilih mengembangkan, mengorganisasikan, materi yang akan disampaikan pada siswa agar materi tersebut dapat diterima, dicerna atau dipelajari siswa sesuai dengan tujuan atau kemampuan yang diarapkan (Uno, 2008:27).

(5) Kegiatan Terapi

Kegiatan belajar mengajar adalah terjadinya interaksi antara guru dan anak didik dengan bahan sebagai perantaranya (Djamarah, 2010:115).

(6) Metode

Metode merupakan suatu cara yang digunakan untuk mencapai tujuan. Beberapa macam metode yang dapat digunakan guru dalam kegiatan belajar mengajar (Uno, 2008:33-38).

(7) Alat/Media

Dalam proses belajar mengajar kehadiran media mempunyai arti yang cukup penting, karena dalam kegiatan tersebut ketidak jelasan bahan yang disampaikan dapat dibantu dengan menghadirkan media sebagai perantara (Djamarah, 2010:120).

(8) Evaluasi

Evaluasi merupakan kegiatan yang mengukur dan menilai. Pengukuran adalah kegiatan untuk mengadakan informasi berupa data kuantitatif, 
sedangkan menilai kegiatan untuk mendapatkan data yang kualitatif. Alat yang digunakan untuk mengukur adalah tes dan non tes. Hasil pengukuran berupa skor (Uno, 2008:44).

\section{METODE PENELITIAN}

Metode yang digunakan dalam penelitian adalah metode kualitatif yaitu dengan mendeskripsikan proses terapi dan manfaat terapi tari pada penderita gangguan jiwa (skizofrenia) melalui Tari Jathilan. Pendekatan penelitian menggunakan fenomenologi yang menekankan pengamatan pada proses terapi berlangsung.

Observasi dilakukan guna melihat bagaimana proses terapi tari pada rehabilitan gangguan jiwa di Rumah Sakit Jiwa Magelang berlangsung. Wawancara dilakukan dengan informan kunci atau sumber data utamanya adalah terapis Bapak Eko Sunyoto, psikologi Ibu Yanti dan penderita gangguan jiwa skizofrenia. Dokumentasi, pengambilan rekaman wawancara, pengambilan gambar, serta dokumentasi mengenai proses terapi.

Keabsahan data menggunakan teknik triangulasi dimaksudkan untuk mendapatkan hasil yang valid, dengan mengecek kembali sumber data yang didapat dari hasi observasi, wawancara, dan dokumentasi saat terjun di lapangan, maka hasil penelitian yang diperoleh dapat dipertanggung jawabkan. Teknik analisis data adalah proses mencari dan menyusun secara sistematis data yang diperoleh dari hasil wawancara, catatan lapangan, dan dokumentasi, dengan cara mengorganisasikan data ke dalam kategori, menjabarkan ke dalam unit-unit, melakukan sintesa, menyusun ke dalam pola, memilih mana yang penting dan yang akan dipelajari, dan membuat kesimpulan sehingga mudah dipahami oleh diri sendiri maupun orang lain (Sugiyono, 2009:244).

\section{HASIL PENELITIAN}

Rumah Sakit Jiwa Prof.dr. Soerojo Magelang terletak di Jalan Ahmad Yani 169 Magelang. Rumah sakit ini terletak 4 kilometer dari pusat kota Magelang, ditepi jalan raya yang menghubungkan kotakota : Yogyakarta, Semarang dan Purworejo, dikelilingi Gunung-gunung Merapi, Merbabu, Andong dan Telomoyo disebelah timur, Ungaran disebelah utara, Sumbing serta Menoreh disebelah barat dan bukit Tidar disebelah selatan.

Fasilitas yang terdapat pada Rumah Sakit Jiwa Prof. dr. Soerojo Magelang cukup memadai seperti: (1) Instalasi Rawat Jalan, (2) Instalasi Rawat Inap, (3) IGD (Instalasi Gawat Darurat), (4) Instalasi Kesehatan Jiwa Anak dan Remaja, (5) Instalasi Kesehatan Jiwa Masyarakat, (6) Instalasi Rehabilitasi Medik, (7) Instalasi Penunjang Medik, (8) Instalasi Farmasi, (9) Instalasi Rehabilitasi Psikososial, (10) Instalasi Pendidikan dan Pelatihan, (11) Instalasi Penelitian dan Pengembangan, (12) Instalasi Gizi, (13) Instalasi Kesehatan Lingkungan/Pengilahan Limbah, (14) Instalasi Binatu, (15) Instalasi Administrasi Pasien dan Verifikasi Klaim, (16) Intensive Care Unit.

Penelitian Tari Jathilan Sebagai Terapi Pada Rehabilitan Gangguan Jiwa di Rumah Sakit Jiwa Magelang bagian yang digunakan sebagai objek penelitian yaitu pelayanan Rehabilitasi Psikososial yang termasuk dalam Pelayanan Kesehatan Jiwa. Sedangkan Instalasinya yaitu Instalasi Rehabilitasi Psikososial. Banyak kegiatan yang dilakukan dalam Instalasi Rehabilitasi Psikososial diantaranya yaitu terapi tari.

\section{Proses Terapi Pada Penderita Rehabilitan Gangguan (Skizofrenia)}

Proses pelaksanaan terapi pada rehabilitan gangguan jiwa melalui Tari Jathilan di Rumah Sakit Jiwa Magelang didukung dengan adanya terapis/pengajar, 
rehabilitan, tujuan, bahan terapi, kegiatan terapi, metode, alat/media, evaluasi. Unsur-unsur tersebut dapat dijelaskan seperti dibawah ini:

(1) Terapis/Pengajar

Pengajar dalam seni tari di Rumah Sakit Jiwa Magelang merupakan seorang pengajar yang mempunyai latar belakang di bidang seni yaitu Bapak Eko Sunyoto. Banyak hal-hal baru yang harus terus di kembangkan oleh beliau seperti, cara mengajar, materi, dan memerlukan kesabaran yang tinggi.

(2) Rehabilitan

Pasien dalam penelitian ini adalah penderita Skizofrenia merupakan gangguan kejiwaan yang meliputi gangguan berfikir, bentuk pemikiran, persepsi, efek, rasa terhadap diri, motivasi, perilaku, dan fungsi interpersonal.

(3) Tujuan

Tujuan utamanya adalah rehabilitan dapat mencapai kemandirian dalam aktifitas produtifitas (pekerjaan/pendidikan) serta kemampuan merawat diri (self care) dan kemampuan untuk menggunakan waktu luang.

(4) Bahan Pelajaran Terapi

Bahan terapi yang diberikan kepada rehabilitan gangguan jiwa (Skizofrenia) yaitu Tari Jathilan. Bentuk Tari Jathilan yang digunakan sebagai media terapi menggunakan gerak, irama, dan music yang sederhana agar mempermudah pasien dalam menerimanya.

(5) Kegiatan Terapi

Proses terapi tari yang dilakukan pada rehabilitan gangguan jiwa (Skizofrenia) di Rumah Sakit Jiwa Magelang dilaksanakan selama 5 kali pertemuan. Kegiatan terapi ada 3 bagian yaitu pendahuluan, inti dan penutup. Kegiatan dimulai dengan memberikan materi sedikit demi sedikit, dengan diselingi pertanyaan, motivasi, dan arahan kepada setiap pasien. Tujuannya agar pasien merasa dekat dengan terapis sehingga mempermudah dalam menyampaikan materi. Respon yang muncul dari pasien berbeda-beda, dari yang merespon positif dan negative. Respon positif itu sendiri ditunjukan pasien dengan keaktifanya mengikuti proses terapi, dan kemauan untuk melakukan gerakan yang diberikan terapis. Akhir terapi ditutup dengan terapis memberikan pertanyaan kepada pasien mengenai perasaan pasien setelah mengikuti kegiatan terapi tari. Respon yang diberikan pasien yaitu pasien merasa senang dengan mengikuti kegiatan menari, bahagia, menghilangkan stress, lebih bisa berkonsentrasi, sehat karena mengeluarkan keringat, dan lebih fokus. Sedangkan respon negative dari pasien diantaranya kurang aktif dalam proses terapi tari, susah untuk mengikuti gerakan yang diberikan terapis, kurangnya semangat saat mengikuti proses terapi. Sebagian dari pasien menunjukan respon yang baik saat mengikuti proses terapi tari.

Butuh kesabaran dalam memberikan terapi tari pada pasien rehabilitan ganggua jiwa skizofrenia agar pasien dapat menerima terapi tari dengan baik. Hambatan yang dialami selama proses terapi adalah emosi pasien yang naik turun, keluar masuknya pasien.

\section{(6) Metode}

Metode yang digunakan dalam proses terapi pada rehabilitan gangguan jiwa (Skizofrenia) ini yaitu dengan pendekatan, mengamati, memberikan contoh, dan mengkomunikasikan.

\section{(7) Alat/Media}

Media dan alat yang dimiliki oleh unit rehabilitasi psikosisial berupa alatalat gamelan. Berdasarkan observasi yang dilakukan pada tanggal 4 mei 2015, diperoleh informasi bahwa kegiatan terapi menggunakan alat-alat gamelan untuk mengiringi Tari Jathilan.

(8) Evaluasi

Pertanyaan berupa bagaimana perasaan setelah mengikuti terapi tari. Terapis selalu memberikan motivasi kepada pasien agar cipta, karsa kembali, terapi selalu memanusiakan pasien atau 
berusaha dekat pasien, dan pertanyaan yang utama yaitu bagaimana reaksi, perasaan, mereka setelah mengikuti terapi.

\section{Manfaat Terapi Pada Rehabilitan Gangguan Jiwa Melalui Tari Jathilan.}

Kegiatan terapi yang telah dilakukan pada rehabilitan gangguan jiwa (Skizofrenia) melalui Tari Jathilan di Rumah Sakit Jiwa Magelang ini menemui adanya berbagai faktor yang mempengaruhi proses terapi ini. Faktor yang pertama yaitu terapis tari, Bapak Eko selaku terapis disini mempunyai andil besar dalam proses terapi. Metode yang digunakan dalam menyampaikan materi kepada pasien berbeda dengan pengajar pada umumnya. Terapis harus mempunyai tingkat kesabaran dalam mengadapi pasien yang memiliki keterbatasan jiwa. Karena pada dasarnya pasien gangguan jiwa ini harus ditangani dengan cara yang baik. Pasien tidak suka dengan cara yang kasar hal tersebut akan mempengaruhi kestabilan emosinya. Pendekatan yang dilakukan terapis kepada pasien seperti memanusiakan pasien, memberikan motifasi agar cipta karsanya kembali.

Dari proses terapi yang dilakukan kepada pasien rehabilitan gangguan jiwa melalui Tari Jathilan yaitu pasien adanya tindakan yang muncul selama mengikuti terapi tari. Tindakan yang kurang baik hingga respon yang baik. Respon yang kurang baik muncul ketika pasien sulit untuk diajak melakukan kegiatan ini seperti malas bergerak, asik dengan kegiatanya sendiri, susah fokus dan konstrasi lemah, emosi yang tidak stabil, dan kemauan yang harus dipenuhi. Respon yang baik timbul dari proses terapi pertama ke terapi selanjutnya seperti, pasien mulai mengembalikan kepercayaan dirinya yang hilang akibat permasalah yang dialami, motivasi mulai muncul, tingkat kemandirian semakin bertambah, ketergantungan mulai hilang, dan sistem motorik pasien semakin baik.
Perubahan sikap yang terjadi pada pasien rehabilitan gangguan jiwa ini merupakan perubahan dari segi perilaku, kebiasaan, perasaan yang membawa pasien dalam ketenangan jiwa. Sikap yang sering muncul seperti cara berfikir yang tidak sesuai dengan kenyataan atau banyak berkhayal, memiliki persepsi yang berbeda dengan orang pada umumnya, motivasi diri yang kurang seakan terpuruk, perilaku yang menyimpang atau tidak wajar seperti orang pada umumnya.Salah satu pengaruh yang timbul karena mengikuti terapi tari yaitu melatih kemandirian pasien, kualitas hidup rehabilitan membaik, menghilangkan ketergantungan, memberikan motivasi psikis kepada pasien, dan melatih keseimbangan motorik (wawancara, Yanti 27 Mei 2015). Mempersiapkan kembali pasien untuk kembali ke masyarakat merupakan tujuan lain dari terapi tari sendiri. Sedangkan manfaat yang diberikan kepada pasien dari terapi tari itu sendiri adalah; (1) Rehabilitan mampu melatih koordinasi gerak motorik dengan hitungan dan gerak, (2) Rehabilitan mampu berkonsentrasi berfikir, (3) Menyalurkan energi positif kepada tubuh rehabilitan, melalui gerak tari, (4) Meningkatnya kemandirian dan produktifitas rehabilitan. Manfaat yang ditelah dijelaskan tesebut bukan mengajari agar mereka pintar menari saja namun, lebih kepada memunculkan perasaan yang hilang karena mengalami gangguan kejiwaan. Salah satu media untuk mewujudkan itu adalah melalui Tari Jathilan.

\section{SIMPULAN}

Tari Jathilan sebagai terapi pada rehabilitan gangguan jiwa di Rumah Sakit Jiwa Magelang adalah penelitian yang memfokuskan pada hal-hal yang dilakukan oleh terapis/pengajar dan rehabilitan gangguan jiwa (Skizofrenia) pada saat proses terapi berlangsung. Mendeskripsikan proses terapi dan 
menjelaskan manfaat yang ditimbulkan dari proses terapi melalui Tari Jathilan ini. Dalam proses terapi didukung dengan adanya terapis/pengajar, rehabilitan, tujuan, bahan pelajaran terapi, kegiatan terapi, metode, alat/media, evaluasi. Pengaruh terapi tari ini yaitu memberikan perubahan yang positif pasien dari segi perilaku, kebiasaan, dan perasaan.

Sikap yang sering muncul seperti cara berfikir yang tidak sesuai dengan kenyataan atau banyak berkhayal, memiliki persepsi yang berbeda dengan orang pada umumnya, motivasi diri yang kurang seakan terpuruk, perilaku yang menyimpang atau tidak wajar seperti orang pada umumnya.Faktor pendukung dalam proses terapi ini yaitu terapis/pengajar yang kreatif, berpengalaman, dan dapat menyiasati keterbatasan dari rehabilitan gangguan jiwa (Skizofrenia) maupun dari sarana prasarana di Rumah Sakit Jiwa Magelang. Faktor penghambat dari proses terapi yaitu sasaran pencapaian pada pasien karna keluar masuknya pasien dan kondisi labil pasien.

Saran dalam penelitian bagi terapis diharapkan menyusun rencana mengajar yang sistematis yang digunakan dalam proses terapi tari, pihak yang membantu dalam proses terapi (terapis lainnya) berperan aktif dalam membantu proses terapi tari, terapis lebih meningkatkan efektifitas dan ativitas dalam terapi tari. Bagi Rumah Sakit Jiwa Magelang diharapkan menambah fasilitas sarana prasarana seperti ruang kesenian, alat musik, kostum yang dapat digunakan untuk proses terapi tari.

\section{UCAPAN TERIMAKASIH}

Penulis mengucapkan terimakasih kepada pihak-pihak yang membantu kelancaran penulisan artikel ini, yaitu: (1) Prof. Dr. Fathur Rokhman, M.Hum, Rektor Universitas Negeri Semarang, (2) Prof. Agus Nuryatin, M.Hum, Dekan Fakultas Bahasa dan Seni Universitas Negeri
Semarang, (3) Joko Wiyoso, S.Kar., M.Hum, Ketua Jurusan Seni Drama Tari dan Musik, (4) Prof. Dr. M. Jazuli, M.Hum dan Dra. V. Eny Iryanti, M.Pd selaku Dosen Pembimbing (5) Rumah sakit Jiwa Magelang (6) Bapak dan Ibu serta seluruh keluarga besar (7) Dinta Candra P.A, Patriadika Hanung P.A, Akhmad Zaki, Widya Susanti (sanggar Bugenvile, (10) Seluruh dosen dan staf karyawan Fakultas Bahasa dan Seni terutama di Jurusan Pendidikan Seni Drama Tari dan Musik khususnya

Pendidikan Seni Tari.

\section{DAFTAR PUSTAKA}

Hartono. 2013. Pendidikan Seni Memacu Potensi Anak, Memicu Konservasi seni Tradisi. Semarang: Fakultas Bahasa Dan Seni Universitas Negeri Semarang.Febrianto, Nurul Aufa. 2013. Persepsi Masyarakat tentang Kesenian Reog di Desa Tengaran Kabupaten Semarang. Skripsi. Universitas Negeri Semarang, Semarang.

Jazuli, M. 2008. Pendidikan Seni Budaya. Semarang: UNNES PRESS

Kuswarsantyo. 2014. Seni Jathilan Dalam Dimensi Ruang dan Waktu. Dalam Jurnal Kajian Seni, Vol. 01 No. 01 November 2014.Pendidikan Seni Tari, FBS, UNY.

Herawati, Nanik. 2009. Kesenian Tradisional Jawa. Klaten: PT. Macanan Jaya Cemerlang.

Maloeng, Lexy J. 2007. Metode Penelitian Kualitatif. Bandung: PT. Remaja Rosdakarya.

Sugiyono. 2012. Metode Penelitian Pendidikan (pendekatan Kuantitatif, kualitatif, dan $R \& D)$. Bandung: Alfabeta.

Kartono, Kartini. 2012. Patologi Sosial 3. Jakarta: PT Raja Grafindo Persada.

Nazir, Moh. 2005. Metode Penelitian. Bogor Selatan: Ghalia Indonesia.

Uno, Hamzah. 2008. Perencanaan Pembelajaran. Yogyakarta: Cipta Media. 
Djamarah, Syaiful Bahri. 2010. Strategi Belajar Mengajar. Jakarta: Rineka Cipta.

Coray, Gerald. 2010. Teori dan Praktek Konseling dan Psikoterapi. Bandung: PT. Refika Aditama.

Palmer, Stephen. 2010. Konseling dan Psikoterapi. Yogyakarta: Pustaka Pelajar

Litfiah. Psikologi Abnormal. Hand out: UNNES.

Ambarwangi, S., \& Suharto, S. (2014).

REOG AS MEANS OF
STUDENTS' APPRECIATION AND CREATION IN ARTS AND CULTURE BASED ON THE LOCAL WISDOM. Harmonia: Journal Of Arts Research And Education, 14(1), 37-45. doi:http://dx.doi.org/10.15294/harm onia.v14i1.2789

Maryono, -. (2011). REOG KEMASAN SEBAG AIASET PARIWISATA UNGGULAN KABUPATEN PONOROGO (The Packes Reog as the high tourism ofPonorogo residence). Harmonia: Journal Of Arts Research And Education, 8(2). doi:http://dx.doi.org/10.15294/harm onia.v8i2.788

Wiyoso, J. (2012). KOLABORASI ANTARA JARAN KEPANG DENGAN CAMPURSARI: SUATU BENTUK PERUBAHAN KESENIAN TRADISIONAL. Harmonia: Journal Of Arts Research And Education, 11(1). doi:http://dx.doi.org/10.15294/harm onia.v11i1.1497

Putra, B. (2013). PENGEMBANGAN MODEL KONSERVASI KESENIAN LOKAL SEBAGAI KEMASAN SENI WISATA DI KABUPATEN SEMARANG. Harmonia: Journal Of Arts Research And Education, 12(2). doi:http://dx.doi.org/10.15294/harm onia.v12i2.2525

Irianto, A. (2016). The Development of Jathilan Performance as an Adaptive Strategy Used by Javanese Farmers. Harmonia: Journal Of Arts Research And Education, 16(1), 3848.

doi:http://dx.doi.org/10.15294/harm onia.v16i1.5213 